\title{
AN INQUIRY INTO THE ROLE OF L3 PROFICIENCY ON CROSSLINGUISTIC INFLUENCE IN THIRD LANGUAGE ACQUISITION
}

\author{
Laura Sánchez, Stockholms Universitet ${ }^{1}$ \\ Email: laura .sanchez@su .se
}

\begin{abstract}
With the rise of multilingualism, studies have proliferated that investigate the interaction of the different languages. The study presented here sets out to examine the role that proficiency plays on the occurrence of a specific interaction, namely interlanguage transfer from a prior non-native language (L2 German) upon another non-native language (L3 English) at the level of syntax in Spanish/ Catalan bilinguals . Data were collected from 80 learners of L3 English who were at different proficiency levels (as indicated by a 30-item cloze test), while data for the analysis of transfer was elicited using a story telling task. Statistical tests revealed significant differences across proficiency levels, i.e. low and pre-intermediate $(\mathrm{p}=.032)$, low and intermediate levels $(\mathrm{p}=.000)$, and pre-intermediate and intermediate levels $(\mathrm{p}=.018)$.

Keywords: interlanguage transfer; crosslinguistic influence; third language acquisition; proficiency; instructed acquisition.

Título en español: "Una indagación sobre el papel de la proficiencia en L3 sobre la influencia transversal en la adquisición de terceras lenguas"

Resumen: Con el crecimiento del multilingüismo, han proliferado los estudios que investigan la interacción entre diferentes lenguas. El presente estudio se plantea examinar el rol que desempeña la proficiencia en la ocurrencia de un tipo específico de interacción, a saber, transferencia entre interlenguas de una lengua no nativa (L2 Alemán) a otra lengua no nativa (L3 Inglés) a nivel sintáctico en bilingües Castellano/ Catalán. Se recogieron datos de 80 aprendices de L3 Inglés que estaban en diferentes niveles de proficiencia (como indicó un cloze test de 30 ítems), mientras que los datos para el análisis de la transferencia se elicitaron empleando una tarea narrativa . Los tests estadísticos realizados revelaron diferencias significativas entre niveles bajo y preintermedio $(\mathrm{p}=.032)$, bajo e intermedio $(\mathrm{p}=.000)$ y pre-intermedio e intermedio $(\mathrm{p}=$ .018) .

Palabras Clave: transferencia entre interlenguas; influencia transversal; adquisición de terceras lenguas; proficiencia/ competencia; adquisición instruida.
\end{abstract}

\section{INTRODUCTION}

Studies on the acquisition of a foreign language beyond the L2, that is, the acquisition of a third or additional language (TLA) have proliferated over the last twenty years . Within this broad field of investigation, most attention has been paid to transfer or

\footnotetext{
${ }^{1}$ Date of reception: 12 August 2014

Date of acceptance: 3 November 2014
} 
crosslinguistic influence (CLI) among the various languages of the multilingual learner, along with the benefit or damage that knowledge of three or more languages may bring about on subsequent language learning. Within this line of investigation, one of the areas that has captured a great deal of attention from the TLA research community is the role that L3 or target-language proficiency (henceforth L3P) plays on the occurrence or nonoccurrence of CLI from the native language (L1) or a prior non-native language (L2) upon the acquisition of a third or additional language (L3) .

Despite the interest shown in L3P, there are still a number of issues that deserve further consideration. With this in mind, the purpose of the review presented in the forthcoming sections has the purpose of revisiting them, by a) pointing out inconsistencies, inaccuracies and impreciseness in the definition of the construct, b) discussing methodological problems in the operationalization of L3P and its measurement, and c) identifying empirical gaps in previous research on the effects of L3P on CLI, with a focus on influence that comes from the L1 (and especially) from the L2. Following De Angelis and Selinker (2001) and DeAngelis (2005a,b), the specific kind of influence caused by the L2 on the L3 will be referred to in this paper as interlanguage transfer. These issues are covered in Section 2 .

\section{BACKGROUND OF THE STUDY}

\subsection{Defining the construct proficiency}

Understanding the dynamics of L3P in TLA should be a prerequisite for an adequate definition of the construct, which should, in turn, embrace the unique characteristics of the concurrent or consecutive acquisition of more than one non-native language. In this sense, different definitions have been put forward to portray the essence of this uniqueness. Two well-known attempts to define proficiency in this scenario are 'multicompetence' and 'multilingual proficiency'. Within the multicompetence framework (Cook, 1992, 1995, 2003), proficiency -internalized knowledge of a given language- or competence -learners' ability to use this knowledge- (see Ellis, 1994; Hulstijn, 2005) is viewed as a whole. To put it another way, it is handled as a distinctive and unique form of language competence that is different from that of monolinguals .

In spite of the explicit concern with the specific roles of the L1 and the L2 "in the creation of knowledge" in subsequent language learning (Cook, 2003: 2-3), the multicompetence framework regrettably does not make testable predictions for the investigation of the potentially differential roles of the L1 and the L2 in the construction of knowledge in the L3. The identification of these differential roles is necessary in empirical research in TLA, as we shall see throughout the paper . Notwithstanding, what multicompetence higlhlights is the interaction between languages against the sum of monolingual competences in the mind of the L3 learner, as Grosjean (1989) had already anticipated for bilinguals and also for trilinguals (2001) .

A different view of proficiency in TLA (Falk and Bardel, 2011; Montrul, Dias and Santos, 2011; Sánchez, 2011a) is taken in the notion of plurilingual competence, defined 
by the Common European Framework of Reference for Languages (CEF) as a "composite competence" (Council of Europe, 2001: 260). This approach to proficiency in TLA is thus heuristic and holistic, while at the same time it highlights the necessity to look at proficiency taking into consideration the original and complex ways in which the different languages in contact interact and combine (Stratilaki, 2006: 3) . Neither multicompetence nor plurilingual competence sufficiently point out the need to look at individual language competence. For the sake of complementation to these views, analytic approaches to proficiency have a more specific focus on the impact of each language of a multilingual.

In this sense, Coste's (1997: 90) main contribution is the claim that multilingual learners have "proficiency of varying degrees in several languages". From this analytic perspective, his definition highlights the frequently overlooked consideration that the languages of a multilingual are at distinct proficiency levels. This idea of partial competence in different languages is related to a kind of "functional competence with respect to a specific limited objective" (Coste, 1997: 91, emphasis in the original), and it is consonant with the claim that development and competence in each language of a multilingual are uneven (e .g . Cenoz, 2001; Müller-Lancé, 2003). Moreover, proficiency in at least one language is greater in comparison with the other languages, and each language has a "different profile of competences" (Coste, 1997: 90) . In a similar vein, North (1997) and Sánchez (2009) emphasize the need to describe language proficiency at different levels, and make reference to selected aspects of proficiency.

In turn, Herdina and Jessner (2002) also adhere to the view of proficiency as heuristic, although their multilingual proficiency encompasses the analytical approach described in the preceding paragraphs in the importance they give to proficiency in each of the languages of a multilingual. To be more precise, they describe proficiency in each language as the "assumed level of acquired knowledge in the language systems of the multilingual speaker" and "derivable from individual language competence" (57, emphasis added). This is the approach to the investigation of proficiency in a bunch of studies in research on the acquisition of syntactic features in TLA, above all in the literature on the L2 (for a review, see Sánchez 2011b; also Jaensch, 2009; Rast, 2010; Rothman, 2011; Trévisiol, 2006). What seems to be crucial is that any empirical study that explores proficiency effects on CLI should formulate specific hypotheses about proficiency-based developmental changes in the nature and overall incidence of CLI at different levels of L3P .

\subsection{The relationship between L3P and CLI: Some methodological drawbacks}

The relationship between proficiency and CLI in the literature on TLA is not transparent (neither in SLA). Among other things, this is due to the fact that with increasing proficiency in the L3, the influence of the L1 or the L2 on the L3 can, at least from a theoretical point of view, decrease, increase, remain constant, or continually fluctuate, or it can ultimate decrease or increase in a non-linear fashion (Jarvis, 2000: 246247). In spite of this lack of clarity, as regards L3P it is repeatedly claimed that CLI is less conspicuous with increasing L3P, as discussed below. Unfortunately, though, this is 
difficult to prove because of a number of methodological imprecisions that play down the force of this claim .

First and foremost, what exactly is understood by 'proficiency' is somewhat fuzzy. The definitions by Coste (1997) and by Herdina and Jessner (2002) referred to above have hardly been echoed in actual empirical research on the role of proficiency in CLI in TLA. Hence, most studies do not explicit state which kind of competence is being investigated when reference is made to proficiency, or the level of acquired knowledge in relation to which specific feature, property, structure or linguistic level. As a consequence, even though one might infer that general proficiency or overall competence is meant (e.g. Dewaele, 1998; DeAngelis and Selinker, 2001; Hammarberg, 2001; Chen and Leung, 1989; Mägiste, 1985, 1986; Schönpflug, 2000, 2003), there is no exact indication of it.

In addition to this, imprecision regarding the proficiency construct also leaves some gaps concerning the modality of speech production (oral or written). This is serious if we take into account that oral proficiency does not necessarily match written proficiency. In this sense, as Jaensch (2011: 87) indicates, because "oral production can involve performance errors as well as competence errors, it may therefore not necessarily reflect true knowledge of the feature tested". Other imprecisions also include the underestimation of disparate effects at different linguistic levels, since different components of language proficiency do not develop in tandem. In other words, proficiency develops differently in discrete areas of language and competence (Muñoz, 2006; Torras, Navés, Celaya and Pérez-Vidal, 2006). In this sense, Hatch (1983), Odlin (1989), Jarvis (1998) or Ringbom (2001) report unequal proficiency effects on CLI, more obvious in lexis and phonology than in morphology or syntax .

Notwithstanding, two claims are generally accepted. Firstly, because an L3 is an interlanguage grammar (and therefore still under development) it is at a higher risk of being influenced by another non-native language (e.g. Falk and Bardel, 2011; Sánchez, 2011a), especially at lower L3P (Abunuwara, 1992; Ahukana, Lund and Gentile, 1981; Bardel and Lindqvist, 2007; Hammarberg, 2001; Möhle, 1989; Odlin and Jarvis, 2004; Ringbom, 1987, 2001, 2007; Sayehli, 2001; Sikogurika, 1993; Taylor, 1975; Vogel, 1992). Thus, while strong evidence of interlanguage transfer has been attested on the learning of an L3 at the earliest stages, it diminishes as learning progresses . Furthermore, interlanguage transfer seems to be more likely in low proficient L3 learners who are highly proficient in and intensively exposed to the L2 (Hammarberg, 2001; Ringbom, 2001; Sánchez, 2011a; Williams and Hammarberg, 1998) .

Likewise, in the area of syntax in particular, the occurrence of CLI is also claimed to be more predominant at low L3P. Some evidence that substantiates this claim comes from studies that demonstrate influence of the L1 on the learning or unlearning of a variety of properties related to V2 in an L2 (Andersen, 1984; Beck, 1998; Camacho, Paredes and Sánchez, 1997; Camacho, 1998; Domergues and Lane, 1976; Fathman and Lococo, 1989; Hertel, 2003; Kilborn and Ito, 1989; Rosén, 2001; Schwartz and Sprouse, 1994, 1996; Stutterheim, 2003).

Less strong claims have been made as regards CLI in more proficient L3 learners. Notwithstanding, a commonly accepted view seems to be that learners at higher levels 
transfer to a lesser extent because their better command of the L3 allows them to manipulate the linguistic means at their disposal more efficiently. This is the reason why some authors have suggested that the relationship between proficiency and CLI is inverse as far as target language proficiency is concerned (Herwig, 2001). Moreover, in the area of syntax, proficiency in the target language (no matter whether it is an L3 or an L2) is described as level of development (Montrul, Dias and Santos, 2011) or stage of L3 development (Rothman, 2010) . In these terms, the core notion of proficiency is understood as the 'mastery' or 'command' (Herdina and Jessner, 2002: 130) of linguistic structures. Hence, even though the chance of interlanguage transfer is seemingly higher at low L3P (i .e . associated with limited or incomplete mastery), the few studies that have examined its occurrence at intermediate L3P levels suggest that it is possible still after the initial stages of acquisition (Falk and Bardel, 2011; Rast, 2010; Sánchez, 2011a), even if the underlying mental representation of previously acquired syntactic properties may change over time (Rothman, 2010: 248) .

Consequently, my claim here is that changes in this mental representation should also have an influence on the learners' hypothesis making at different L3P levels, and on their L3 interlanguage development and subsequent restructuring with increasing L3P . Besides, the robust findings obtained in some studies beyond intermediate proficiency levels indicate that some kinds of CLI (at least from the L1) may persist even at advanced stages of acquisition (Carroll, Murcia-Serra, Watorek and Bendiscioli, 2000) . Notwithstanding, a problem that frequently arises in the research design of studies on CLI is the assessment or measurement of target language proficiency. Even though improvements in proficiency in the target language (L2 or L3) are evident over time either due to tuition-related gains in instructed acquisition or to a longer length of residence in the case of naturalistic acquisition (e.g. Fathman and Loco, 1989; Ijaz, 1986; Rounds and Kanagy, 1998), no instrument has been used to have an objective measure of proficiency with a few exceptions such as for instance Falk and Bardel (2011); DeAngelis (2005b); Jaensch, 2011; Rothman, 2010; Sánchez, 2011a; Çiğdem, 2006).

In research on CLI in the acquisition of syntactic properties, the most successful attempts to measure proficiency are Jaensch (2011) and Sánchez (2011a). Jaensch used the Oxford Quick Placement Test to assess the learners' proficiency in L2 English, and the Goethe Proficiency Test for L3 German. The results of these tests were later used to classify learners following the guidelines provided by the CEF. An independent test used as a proficiency measure was employed in Rothman (2010) and in Çiğgem (2006), who administered their learners a cloze test and a C-Test, respectively, in order to measure proficiency in the L3. In contrast to these two studies, Falk and Bardel (2011) did not use any independent proficiency measure to classify their learners. Instead, to do so, the authors assessed their L3 performance in the oral production that was elicited for the data analysis of the targeted structures in the study. In other studies, proficiency is impressionistically assessed on the basis of accumulated instruction or simply grade in instructed acquisition. For example, Montrul et al. (2011: 34) classified their university learners according to the "course level" at the university. In the same way, in Hall, Newbrand, Ecke, Sperr, Marchand and Hayes (2009: 166) the classification relied on the 
"institution's placement policy" (which was supposed to be advanced). Other ways in which proficiency is assessed in the literature on TLA are often self-perceived proficiency reports on the part of the learner (e.g. Hufeisen, 1998; Rast, 2010).

Still, in the L3 acquisition of syntactic properties in general and of complex structures in particular, the incidence of interlanguage transfer is more conspicuous at low L3P if proficiency in the L2 (i.e., the source language of influence) is high. Therefore, it is often reported that for transfer of interlanguage structures to occur at low L3P, learners must reach "a sufficiently high level in their L2" (Falk and Bardel, 2011: 77). Nonetheless, the opposite is also true . DeAngelis and Selinker (2001) found evidence that an L2 in which learners are low proficient can and do indeed influence (at least oral) L3 production, thereby suggesting that a high proficiency in the L2 is not a prerequisite for interlanguage transfer to occur at low L3P. More recently and focusing solely on syntax, the its occurrence has been observed at low L3P in learners whose L2 was intermediate or lower (Sánchez, 2010, 2011a, 2011b, 2011c, Sánchez, in press). The learners of L3 English investigated by Sánchez in various studies exhibited a more varied array of qualitative patterns of interlanguage transfer (from their L2 German) and a higher frequency of occurrence of these patterns when their L2 interlanguage grammar was still underdeveloped. To be more precise, interlanguage transfer in the data of these low proficiency L3 learners was greater when one or more structural properties of the verb second (V2) cluster were not yet fully mastered in the L2. Above all, this was the case of subject-verb inversion in main clauses and verb final in embedded clauses (Sánchez, 2009, 2011a) . Likewise, in same-aged learners matched for L3P, the occurrence of interlanguage transfer was much less pervasive if they had a better command of these structural properties in the L2 .

\section{THE STUDY}

In consonance with the analytical approach outlined in the preceding sections, the study presented here adds to the growing body of literature on the effects of proficiency on CLI . In particular, it examines the role played by L3P, and expands the scope of previous research by exploring data of adolescent multilingual learners who were acquiring the L3 in an instructed setting. The remaining of the paper is organized as follows . The exact research question addressed in the study is presented in Section 4, followed by the presentation of the participants (Section 5) and of the data collection and procedure (Section 6). This is followed by the description of the data analysis (Section 7), the results of which are reported in Section 8 and discussed in Section 9, which also offers the conclusions of the study and the directions for future investigation .

\section{4 . RESEARCH QUESTIONS}

The study presented here investigates the role that proficiency in the target language (that is, L3P) plays on the occurrence of interlanguage transfer from a prior non-native language. Specifically, it inquired into the effects that different L3P levels have on this 
kind of transfer. The linguistic feature selected for the examination of interlanguage transfer is syntax, or to be more precise, verb placement. From now onwards in the paper, the interlanguage transfer of verb placement will be referred to as ILTVP. The question guiding the study goes as follows:

RQ: Does target language proficiency (in this case L3 English) affect the occurrence of ILTVP from L2 German into the L3 English?

\section{PARTICIPANTS}

In order to answer the RQ posed above, the study relied on data from 80 third language learners of English . These learners were native speakers of Spanish and Catalan, and they were bilingual in these languages to different extents. In addition to L3 English, they had knowledge a prior non-native language, namely L2 German. They were acquiring both the L2 and the L3 in an instructed acquisition setting (for a more detailed description, see Sánchez, in press) .

In the assumption that the occurrence of CLI in general and ILT in particular is more frequent at the earliest stages of L3 acquisition, as indicated in Section 2, it was convenient to gather data from learners in the short-term, i .e . which in the present study corresponds to instruction up to 132 hours or fewer. To this aim, participants were recruited who fell within this range of accumulated instruction. However, it was not practical to try and analyze data from absolute beginners, because the targeted feature (verb placement) requires at least some morphosyntactic knowledge . To put it another way, the learners' restricted lexical, morphological and syntactic resources would limit their ability to express themselves in the L3. Such linguistic restrictions would prevent them from producing an interlanguage that was valid for the present purposes (cf . with Kaltenbacher, 2001: 212) . Bearing this in mind, data were collected from learners who had received at least 50 hours of instruction in the target language. More precisely, they had received between 55 and 132 hours of curricular exposure at school, and none of them had been exposed to the L3 English outside the classroom. Their mean ages at the time of data collection were 11.9 and 12.9 . The comparability of the two age groups was guaranteed, as a paired samples t-test revealed that there was no statistically significant difference between them as far as the occurrence of ILTVP was concerned $(p=.587)$. Table 1 summarizes all this information:

\begin{tabular}{|l|l|l|l|}
\hline \multirow{2}{*}{ MEAN AGES } & \multicolumn{3}{|c|}{ INSTRUCTIONAL TIMES } \\
\cline { 2 - 4 } & $55 \mathrm{Hrs}$. & $99 \mathrm{Hrs}$. & $132 \mathrm{Hrs}$. \\
\hline 11.9 year-olds & $n=0$ & $n=15$ & $n=15$ \\
\hline
\end{tabular}




\begin{tabular}{|l|l|l|l|}
\hline 12.9 year-olds & $n=22$ & $n=0$ & $n=28$ \\
\hline
\end{tabular}

Table 1. Overview of the participants

\section{DATA COLLECTION AND PROCEDURE}

The data collection consisted of three tasks, which are described below in more detail . The first one was a narrative task, and it supplied the linguistic material necessary for examining the occurrence of ILTVP from L2 German in L3 English production . The second task was a cloze test, which was employed in order to measure the learners' L3P. Finally, a language background questionnaire was administered to all potential participants, in order to select the learners and identify outliers .

\subsection{Elicitation technique}

The data from the narrative task was elicited using a Story Telling Task called 'The Dog Story' (Heaton, 1966; Sánchez and Jarvis, 2008), based on a six-picture cartoon. This is a written task, and it is part of the battery of tests we use in the GRAL Research Group ${ }^{2}$ in a number of projects such as $\mathrm{BAFiA}^{3}$ (currently at work at the University of Barcelona)

The task was time-controlled (ca . 10-12 minutes) . It was not familiar to the learners, and it was administered to them in class to the intact groups. They were given a sheet with the six pictures of the story, and a separate white sheet to write the story . The participants were not allowed to ask questions related to the vocabulary of the story, neither to use a dictionary, grammar book, or similar reference tools . The activity was carried out under the supervision of their teacher and the researcher (in this case, the author of this study) . Learners had no time preparation, but they had the series of pictures in front of them while doing the task .

\subsection{Cloze Test}

In order to obtain an independent L3P measure, learners were asked to fill-in a 30item Cloze Test based on the 'Little Red Riding Hood' . This task was chosen because the cloze test is meant to be an indicator of overall proficiency (e.g. Katona and Dörnyei, 1993; Muñoz, 2006; Sánchez, 2011a).

\footnotetext{
2 ‘Grup de Recerca en Adquisició de Llengües’ (Language Acquisition Research Group) .

${ }^{3}$ The BAFiA Project (Barcelona Age Factor, Input and Attitude) is funded by a Grant FFI2010-21478 by the Spanish Ministry of Education, and also to grant 2014SGR1089 by the Catalan Government .
} 


\subsection{Questionnaire}

The background language questionnaire was adapted from Sánchez (in press) . It was used in order to gather information on the linguistic background of the participants, and to make decisions on their inclusion in the study. The items in this questionnaire included questions on the L1(s) and knowledge of foreign languages, age of onset in the learning of the L2 and the L3, extracurricular exposure, as well as home and family languages .

\section{Data analysis}

The analysis of the data was two-fold . On the one hand, the data from the narrative task was used in order to explore the occurrence of ILTVP from the L2 in relation to verb placement. On the other hand, the learners' performance in the cloze test was used in order to classify them into three L3P groups: low, pre-intermediate, and intermediate . These are described in more detail in Sections 7.1 and 7.2 .

\subsection{Targeted linguistic feature}

The targeted linguistic feature was verb placement . Verb placement is head-initial in languages such as English (L3), Spanish and Catalan (L1s), but head-final in German (L2) . That is to say, word order as regards verb placement is congruent in the L1s and the target language, but different in the source language of influence investigated here. To put it short, the placement of the verb in main clauses follows the rule of verb separation or discontinuous verb placement, by which the finite verb (i.e. tense and modal auxiliaries) occupies the second position in the clause, whereas non-finite verbs (i.e. infinitives and participles) appears at the end of the clause, as in (1-3) below .

(1) "Peter hat gerade einen Brief geschrieben"

* Peter has just a letter written

(Peter has just written a letter)

(2) "Peter will ins Kino gehen"

* Peter wants to the cinema go (Peter wants to go to the cinema)

(3) "Peter kann ins Kino gehen"

* Peter can to the cinema go

(Peter can go to the cinema)

A similar movement takes place in embedded clauses, whereby the verb final rule forces the entire verb phrase (that is, both thematic and non-thematic verbs) to appear at the end of the clause, as in (4-5). 
(4) “... daß Peter heute ins Kino geht"

* that Peter today to the cinema goes

(that Peter goes to the cinema today)

(5) "... daß Peter heute ins Kino gegangen ist"

* that Peter today to the cinema gone is

(that Peter has gone to the cinema today)

The narratives were inspected in search for contexts were ILTVP of verb placement could occur, that is, empirically-relevant contexts for the investigation of ILTVP . To start, these contexts include complex verb phrases with periphrastic constructions of the kind shown in examples 1, 2, 3 and 5 in main and embedded clauses . Next, they include simple verb phrases in embedded clauses, as in (4) above. A quantitative dependent variable measured the occurrence of ILTVP detected in such contexts . A continuous variable registered the raw occurrences of ILTVP for each participant . To have a more concise view of the picture, this continuous variable was later transformed into a new variable that calculated the percentage of ILTVP in contexts where it could be observed .

\subsection{Proficiency Measurement}

The cloze tests were proofread by the researcher, and the raw scores obtained were transformed into $\mathrm{z}-$-scores . To avoid any arbitrariness in the subsequent use of $\mathrm{z}$-scores to classify participants according to levels of L3P, T-scores were computed on the $\mathrm{z}$-scores . The $\mathrm{T}-$-score is calculated by multiplying the $\mathrm{z}-$-score per 10 and adding 50 . The typical mean of the $\mathrm{T}$-score is 50 , and its standard deviation is 10 . Conventional uses of these scores usually deem high values those higher than 60 . Low scores are equivalent to the mean minus 1 standard deviation (50-10), that is, those below 40 . Scores that fall within 41 and 59 are then considered intermediate . Relying on the T-scores, the participants' classification into L3P levels gave way to the distribution into low, pre-intermediate and intermediate levels presented in Table 2 . Thus, the table presents the number of learners at each level, and the percentage it represents over the total amount of participants . It offers as well the descriptive statistics of the participants' performance in the Cloze Test in terms of means and standard deviation .

\begin{tabular}{lllll} 
LEVEL & $n$ & $\%$ & Mean & tD \\
\hline Beginner & 24 & $\mathbf{3 0} \%$ & 3.33 & 1.551 \\
Pre-intermediate & 47 & $\mathbf{5 8} \%$ & 9.77 & 2.614 \\
Intermediate & 9 & $\mathbf{1 2} \%$ & 16.67 & 3.000 \\
\hline
\end{tabular}

Table 2. Participants' classification according to L3P: 


\section{RESULTS}

The RQ guiding the study asked whether L3P had any effect on the occurrence of ILTVP from L2 German to the L3 English. Before answering this question, the description of the results starts with an illustration of the kind of ILTVP encountered in the corpus, as shown in the examples below. This is followed by a report of the descriptive statistics of the raw frequency of instances of ILTVP found. For a more through account of the occurrence of this type of interlanguage transfer see Sánchez (2011a, b) . The transferred verb placements are italicized . Examples (6) to (11) below illustrate the occurrence of ILTVP in main clauses:

(6) "and the dog has everything eat"

(7) "the dog have the breakfast eat"

(8) "The dog has the lunch eating"

(9) "They is the food eating"

(10) "The dog had the breakefas ate"

(11) "He have all the Sandwich and the cake ate"

In turn, some instances of ILTVP in embedded clauses are the following, both with simple (12) and complex (17) verb phrases . As can be seen, in some cases the verb placement transferred in embedded clauses did not correspond to verb final (as in 17), but to SEP (as in 16):

(12) "When the kids and your mother near o the table are"

(13) "When he the boetel in the hand have"

(14) "wen the boy the baskett see"

(15) "because the dog all the lunch eat"

(16) "that the dog has all the food eating"

(17) "... why ${ }^{4}$ the dog the sandwiches eat have"

The report of the results starts with the descriptive statistics of the raw frequency of instances of ILTVP encountered in the data. All in all, a total of 64 occurrences were detected in the database. The way they were distributed is presented in Table 3, which offers the total number of contexts where ILTVP could occur, the raw frequency of occurrence of transfer in these contexts, and the percentage that ILTVP represents at each proficiency level.

\begin{tabular}{llll} 
LEVEL & $\begin{array}{l}\text { Empirically } \\
\text { Relevant Contexts }\end{array}$ & ILTVP (Raw) & ILTVP (\%) \\
\hline Beginner & 30 & $\mathbf{2 3}$ & $\mathbf{7 6 . 7 \%}$
\end{tabular}

\footnotetext{
${ }^{4}$ In this example . "why" is used instead of "because".
} 


\begin{tabular}{llll} 
Pre-intermediate & 91 & $\mathbf{3 9}$ & $\mathbf{4 2 , 9 \%}$ \\
Intermediate & 21 & $\mathbf{2}$ & $\mathbf{9 , 5 \%}$ \\
\hline TOTAL & 142 & $\mathbf{6 4}$ & \\
\hline
\end{tabular}

Table 3. Raw frequency \& Percentage of ILTVP across L3P levels

Next, Table 4 presents the distribution of the occurrences of ILTVP across L3P levels . This table shows that most instances were found at the pre-intermediate proficiency level, even if the percentage that ILTVP represented (over the total number of contexts where it could occur) was lower at this L3P than at the beginners' level, as shown in Table 3 .

\begin{tabular}{lcc} 
LEVEL & Raw Frequency & Percentage \\
\hline Beginner & 23 & $\mathbf{3 6} \%$ \\
Pre-intermediate & 39 & $\mathbf{6 1} \%$ \\
Intermediate & 2 & $\mathbf{3} \%$ \\
\hline
\end{tabular}

TOTAL

64

Table 4 . Distribution of ILTVP across L3P levels

It is worth to recall at this point that in order to describe the scene in as comprehensive a way as possible, the representativeness of ILTVP in each learner was offered in a variable that calculated the percentage of occurrence of ILTVP (that is, the ratio of ILTVP) . Hence, Table 5 offers the descriptive statistics pertinent to the occurrence of ILTVP across L3P levels, which is followed by a description of the statistical tests run on this ratio .

\begin{tabular}{|c|c|c|c|}
\hline DESCRIPTIVE STAT. & LOW & PRE-INTERM. & INTERM. \\
\hline \multicolumn{4}{|l|}{ Central Tendency } \\
\hline Mean & 75.833 & 49.145 & 6.944 \\
\hline Median & 100.0000 & 50.0000 & .0000 \\
\hline
\end{tabular}




\begin{tabular}{|l|l|l|l|}
\hline Mode & 100.00 & $.00 *$ & .00 \\
\hline Dispersion & .00 & .00 & .00 \\
\hline Minimum & 100.00 & 100.00 & 25.00 \\
\hline Maximum & & \\
\hline
\end{tabular}

* Multiple modes exist. The smallest value is shown

Table 5 . Descriptive statistics of the ratio of ILTVP across L3P levels

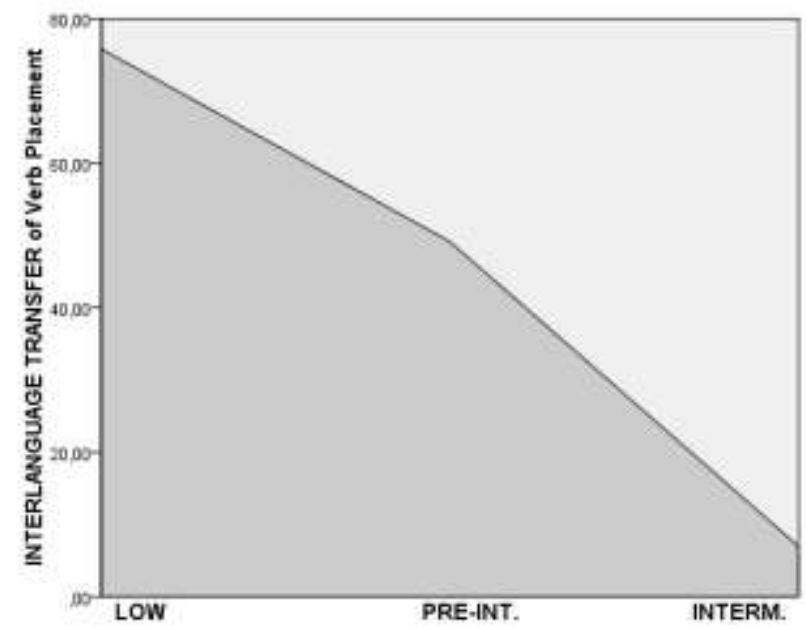

Figure 1. Decreasing pattern of ILTVP at low, pre-intermediate \& intermediate L3P levels

The statistical test used in order to find out whether the differences across L3P levels were significant was a paired samples t-test. These tests yielded statistically significant differences in all of the comparisons, namely, between low and pre-intermediate levels $(\mathrm{p}=.032)$, low and intermediate levels $(\mathrm{p}=.000)$, and finally between pre-intermediate and intermediate levels $(\mathrm{p}=.018)$. To conclude the results section, Figure 1 shows the pattern of decreasing ILTVP at the three L3P described in the preceding paragraphs . 


\section{DISCUSSION AND CONCLUSIONS}

The study presented here asked whether L3P would any effect on the way the activation of already existing knowledge regarding verb placement in a previous L2, resulting in various extents of transfer into an L3. The evidence assembled suggests that it was actually the case. The following paragraphs discuss the relationship between L3P and ILTVP observed in the data, and then it goes on to provide an answer to the research question that guides the study .

Hence, L3P was found to affect the activation and transfer of verb placement from the L2 German. In view of the results reported in Section 8, the main finding is that a low level of L3P pushed the activation of L2 knowledge, thereby boosting ILTVP. The means and manner in which L3P constrained the occurrence of ILTVP needs to be understood in relation to the stage of $\mathrm{L} 3$ acquisition of the learners investigated here . Let us remember that the study focused on the interlanguage of learners in the short term within the first 200 hours of instruction in L3 English. Therefore, the claims made in what follows are pertinent to the development of early interlanguage grammars, when the learners' curricular exposure is still fairly limited. In this sense, the assertion that different levels of L3P discriminate between varying extents of ILTVP already at such early stages of L3 acquisition is an important finding, and much telling about the general role of the proficiency factor and CLI in TLA at a more theoretical level. Furthermore, it is a solid point of departure for further research, and for future studies on the role of L3P in more mature grammars at upper intermediate and advanced proficiency levels.

The figures in Tables 3 and 4 are particularly informative of the accumulation of instances of ILTVP at low and pre-intermediate L3P levels . If only its raw frequency of occurrence is taken into account, then one may come up with a distorted view of what is actually going on. The figures in Table 3 indicate that out of the bunch of instances of ILTVP detected in the database, 39\% were observed at low L3P levels, but an even higher percentage (61\%) was found at pre-intermediate levels . However, if the amount of ILTVP is looked at in relative terms as a ratio of ILTVP over the total number of contexts where it could occur, then the picture is more realistic . In objective terms, the data in Table 4 reveals that when the ratio is taken as the dependent variable, the means at the two L3P levels are different, with that at low proficiency levels (75.833) being higher than that pre-intermediate levels (49.145) .

From this it follows that low L3P learners transferred more than their more proficient peers and they had serious difficulties in blocking the influence of the L2, at least as regards the ILTVP of verb placement under examination here . By way of contrast, at more intermediate L3P levels, learners were in a better position to inhibit activation and ILTVP . In other words, an intermediate proficiency level in the target language seemed to accelerate the rate with which transfer of verb placement was abandoned . Additionally, it seems that until the learners investigated reached an intermediate L3P, the limited input they were receiving in this language was not optimal in terms of time and efficiency, neither in intensity nor in extent (Muñoz, 2008). This shortage might well aid in explaining why the incidence of ILTVP was so high (a mean of 75.833 and of 49.145 at 
low and pre-intermediate levels, respectively, against a 6.944 at the intermediate level investigated here, as shown in Table 4). Hence, until an intermediate proficiency level is reached, learners did not seem to benefit from positive evidence, and to notice the crucial structural contrasts between L2 German and L3 English that would lead them to successful acquisition of verb placement in the target language .

Following Schmidt's (2001: 5) consideration that the acquisition process is driven by what learners pay attention to and notice in the L3 input they are exposed to, it wouldn't be unreasonable to claim that (at least within the short term), an intermediate L3P level is the minimum required for learners to pay attention to some features of surface structure such as the position of the verb in the verb phrase . Likewise, before this level is reached, the poor input learning conditions just described would be argued not to be auspicious for the learners to notice the crucial structural contrasts between English (L3) and German (L2), and to become aware of differences in verb placement and surface structure .

Furthermore, the findings link also with the question of activation of existing memory and stored linguistic knowledge of a previous L2 . This may build a bridge between L3P and related cognitive factors such as working memory and long-term memory. By the same token, these findings on L3P also link with the learners' simultaneous attention to and control of forms, features and structures in their weaker and least proficient language, and also in an L2 already acquired or in the process of being acquired . This account of the results of the present study would speak to the explanatory weight of cognitive factors within a broad theory of language transfer (Odlin, 2009; Falk and Bardel, 2010; Sánchez, 2011a; Bardel and Falk, 2012). Likewise, it would point at the suitability of an information processing approach as a framework for the investigation of TLA .

From an information processing approach, it seems wise to claim that the processing involved in L3 production of the learners in this study was controlled. This controlled production requires the activation of a limited number of information nodes in the execution of speech . Moreover, the high incidence of ILTVP observed suggests that controlled processing is heavily conditioned by reliance on interlingual connections and associative chains between the non-native languages. These nodes (for example, L3 English 'has', L2 German 'hat' and their fellow structures) are stored in phonological short-term memory, and called for retrieval through working memory (Sánchez, 2011a) .

In contrast to this controlled processing, and given that learners had a greater exposure to the L2 and presumably also a higher proficiency level in this language, they may have presumably had a more automatized knowledge (Doughty, 2001; Robinson, 1995; TaubeSchiff and Segalowitz, 2005) of the source language of influence, in this case the L2. It is also possible that automatic processing of the L2 during L3 production also contributes to reducing the burden on the learners' information processing capacity . Interesting as these interpretations may be, further investigation at the lexico-syntactic interface is needed that further inquiries into the connection and activation of structures in TLA, and the role that factors such working memory and short-term memory plays on it . 


\section{REFERENCES}

abunuWaRa, e. 1992 . "The structure of the trilingual lexicon" . European Journal of Cognitive Psychology 4: 311-322.

ahukana, j., lund, n., and gentile, j. 1981 . "Inter- and intra-lingual interference effects in learning a third language”. Modern Language Journal 65: 281-287 .

andeRsen, R. 1984 . "The one-to-one principle of interlanguage constructions" . Language Learning 34: 77-95 .

baRdel, c., and lindqvist, c. 2007. "The role proficiency and psychotypology in lexical cross-linguistic influence. A study of a multilingual learner of Italian L3". Atti del VI Congresso di Studi dell'Associazione Italiana di Linguistica Applicata Napoi 910 February 2006. Eds. M. Chini, P. Desideri, M.E. Favilla and G. Pallotti. Perugia . Guerra Editore .

beck, M.1., "12 The role 12 acquisition and obligatory head movement: Englishspeaking learners of German and the Local Impairment Hypothesis" . Studies in Second Language Acquisition 20: 311-348 .

caMacho, j. 1998 . "Is there canonical word order transfer in L2 acquisition?" Boston University Conference on Language Development . Sommerville: Cascadilla .69-

80 . CaRRoll, M., Murcia-SeRRa, j., WatoRek, M., and bendiscioli, a. 2000 . "The relevance of information organization to second language acquisition studies". Studies in Second Language Acquisition 22: 441-466.

Cenoz, j. 2001 . "The effect of linguistic distance, L2 status and age on cross-linguistic influence in third language acquisition". Cross-linguistic Influence in Third Language Acquisition. Eds . j. cenoz, b. huFeisen and u. jessneR. Clevedon: Multilingual Matters . 8-20 .

chen, h. and leung, y. 1989 . "Patterns of lexical processing in a non-native language" . Journal of Experimental Psychology: Learning, Memory and Cognition 15: 316325 .

Çiğdem, S. 2006 . Third Language Acquisition. Turkish-German bilingual students' acquisition of English word order in a German educational setting . Berlin: Waxman .

cook, v . 1992 . "Multicompetence and the learning of many languages" . Language Culture and Curriculum 8: 93-98 .

cook, v . 1995 . "Evidence for multicompetence" . Language Learning 42: 557-591 . . 2003 . Effects of the second language on the first . Clevedon: Multilingual Matters . 
coste, d. 1997 . "Multilingual and multicultural competence and the role of school" . Language Teaching 30: 90-93 .

deangelis, g . 2005 . "Interlanguage transfer of function words" . Language Learning 55: $379-414$.

. 2007 . Third or Additional Language Acquisition . Clevedon: Multilingual Matters .

deangelis, g., and SelinkeR, 1. 2001 . "Interlanguage transfer and competing linguistic systems in the multilingual mind" . Cross-linguistic Influence in Third Language Acquisition. Eds . j. cenoz, b. huFeisen and u. jessner. Clevedon: Multilingual Matters . 42-58 . dewaele, j.M. 1998. "Lexical inventions: French interlanguage as L2 versus L3". Applied Linguistics 19: 471-490 .

DomMeRgues, J-Y., and lane, H . 1976 . "On two independent sources of error in learning the syntax of a second language". Language Learning 26: 111-123 .

doughty, c. 2001 . "Cognitive underpinnings of focus on form" . Cognition and Second Language Instruction. Ed . p. Robinson. Cambridge: Cambridge University Press .

ellis, R . 1994 . "Language transfer" . The Study of Second Language Acquisition . Oxford: Oxford University Press . 471-499 .

Falk, y., and baRdel, c . 2011 . "Object pronouns in German L3 syntax: Evidence for the L2 status factor". Second Language Research 27: 59-82 .

FathMan, a., and lococo, v . 1989 . "Word order contrasts and production in three target languages". Transfer in Language Production . Eds . decheRt and M. Raupauch. Norwood, NJ: Ablex Publishing Corporation. 125-150 gRosjean, F . 1989 . "Neurolinguists, beware! The bilingual is not two monolinguals in one person" . Brain and Language 36: $3-15$.

hall, c., newbRand, d., ecke, p., SpeRR, u., MaRchand, v., and hayes, 1. 2009 . 'Learners' implicit assumptions about syntactic frames in new L3 words: the role of cognates, typological proximity and L2 status". Language Learning 59: 153-203.

hatch, e. 1983. "Simplified input and second language acquisition". Pidgnization and Creolization as Language Acquisition . Ed . R. andeRsen . Rowley: Newbury House . 64-86.

haMMaRbeRg, b. 2001 . "Roles of L1 and L2 in L3 production and acquisition". Crosslinguistic Influence in Third Language Acquisition. Eds . j. cenoz, b. huFeisen and u. jessneR. Clevedon: Multilingual Matters . 21-41

heaton, b. 1966 . Composition through pictures . London: Longman .

heRdina, p., and jessneR, U . 2002 . A Dynamic Model of Multilingualism . Clevedon: Multilingual Matters .

heRtel, t. 2003 . "Lexical and discourse factors in the L2 acquisition of Spanish word order”. Second Language Research 19: 273-304 . 
huFeisen, b. 1998. "L3-Stand der Forschung-Was bleibt zu tun?". Tertiärsprachen: Theorien, Modelle, Methoden. Eds . b. huFeisen and b. lindeMann . Tübingen: Stauffenburg Verlag . 169-184 hulstijn, j. 2005 . "Theoretical and empirical issues in the study of implicit and explicit second language learning". Studies in Second Language Acquisition 27: 129-140 .

ijaz, h. 1986 . "Linguistic and cognitive determinants of lexical acquisition in a second language" . Language Learning 36: 401-451 .

jaensch, c. 2009. "L3 enhanced feature sensitivity as a result of higher proficiency in the L2" . Third Language Acquisition and Universal Grammar . Ed . y. leung .

Clevedon: Multilingual Matters . 115-143 jaRvis, s. 1998 . Conceptual Transfer in the Interlingual Lexicon . Bloomington: Indiana University .

. 2000. "Methodological rigor in the study of transfer: identifying L1 influence in the interlanguage lexicon". Language Learning 50: 245-309 .

kaltenbacheR, M. 2001 . Universal Grammar and Parameter Resetting in Second Language Acquisition. Frankfurt: Peter Lang.

katona, 1., and döRnyei, z. 1993 . "The C-Test: A teacher friendly way to test language proficiency". Forum 31: 34-35 .

kilboRn, k., and ito, t. 1989. "Sentence processing in Japanese-English and DutchEnglish bilinguals". The cross-linguistic study of sentence processing . Eds . b. MacWhinney and e. bates. New York: Cambridge University Press. 257-291

Mägiste, e. 1984 . "Stroop tasks and dichotic translation: The development of interference patterns in bilinguals". Journal of Experimental Psychology: Learning, Memory and Cognition 10: 304-315 .

. 1985 . "Development of intra- and interlingual interference in bilinguals". Journal of Psycholinguistic Research 14: 137- 154 .

. 1986 . "Selected issues in second and third language learning" . Language Processing in Bilinguals: Psycholinguistic and Neuropsychological Perspectives. Ed .vaid. Hillsdale, NJ: Erlbaum. 97-122.

Möhle, d. 1989 . "Multilingual interaction in foreign language production" . Interlingual Processes. Eds . h. w. decheRt and M. Raupauch . Tübingen: Gunter Narr . 179-194 .

MontRul, s., dias, R., and Santos, h. 2011. "Clitics and object expression in the L3 acquisition of Brazilian Portuguese . Structural similarity matters for transfer" . Second Language Acquisition 27: 21-58 .

MülleR-lancé, j. 2003 . "A strategy model of multilingual learning” . Eds . j. cenoz, b. huFeisen and u. jessneR. Dordrecht: Kluwer Academic . 117-132

Muñoz, c. 2006 . Age and the Rate of Foreign Language Learning . Clevedon: Multilingual Matters . 
. 2008 . "Symmetries and asymmetries of age effects in naturalistic and instructed L2 learning”. Applied Linguistics 29: 578-596 .

noRth, b. 1997. "Perspectives on language proficiency and aspects of competence". Language Teaching 30: 93-100 .

Odlin, t. 1989 . Language Transfer . Cambridge: Cambridge University Press .

. 2009 . "Language transfer and the link between comprehension and production" . Paper presented at the International Symposium on Language Transfer in Second Language Acquisition. Shanghai Jiao Tong University. Shanghai, China.

Odlin, t., and jaRvis, s. 2004 . "Same source, different outcomes: A study of Swedish influence on the acquisition of English in Finland". International Journal of Multilingualism 1: 123-140 .

Rast, R. 2010 . "The use of prior linguistic knowledge in the early stages of L3 acquisition”. International Journal of Applied Linguistics 48: 159-183 .

RingboM , h . 1987 . The Role of the First Language in Foreign Language Learning . Clevedon: Multilingual Matters .

. 2001 . "Lexical transfer in L3 production". Cross-linguistic Influence in Third Language Acquisition. Eds . . j. cenoz, b. huFeisen and u. jessneR. Clevedon: Multilingual Matters . 59-68 .

. 2007 . Cross-linguistic Similarity in Foreign Language Learning . Clevedon: Multilingual Matters .

Robinson, p. 1995 . "Attention, memory, and the 'noticing' hypothesis" . Language Learning 45: 283-331.

Rosén, c. 2001. "Deutsch als Fremdsprache: Zur Informationsstruktur schwedischer Deutschstudierender". Moderna Sprak 95: 49-61.

RothMan, j. 2010 . "On the typological economy of syntactic transfer: Word order and relative clause high/low attachment preference in L3 Brazilian Portuguese" . International Review of Applied Linguistics 48: 245-273 . . 2011 . "L3 syntactic transfer selectivity and typological determinacy: The typological primacy model”. Second Language Research 27: 107-127 .

Rounds, p., and kanagy, R. 1998 . "Acquiring linguistic cues to identify Agent: Evidence from children learning Japanese as a second language". Studies in Second Language Acquisition 20: 500-542 .

SÁnchez, 1. 2009 . "Selected effects of L2-L3 proficiency thresholds and asymmetric input on multiple language acquisition". Paper presented at the Eurosla Conference . Cork: Ireland . 
SÁnchez, 1 . 2010 . "Systematicity and variability in over time IL development: developmental sequences in the acquisition of order within VPs in English as a foreign language". ODISEA Revista de Estudios Ingleses 11: 59-83 .

2011a . Crosslinguistic influence in third language acquisition: English after German in Spanish/ Catalan bilingual learners in an instructed setting. Unpublished PhDissertation, University of Barcelona .

$2011 \mathrm{~b}$. 'Luisa and Predito's dog will the breakfast eat: Interlanguage transfer and the role of the second language factor. New Trends in Crosslinguistic Influence and Multilingualism Research. Eds . g. deangelis and j.M. deWaele. Clevedon: Multilingual Matters . 86-104 .

.2011c . "Against 'Canonical word order': evidence of basic word order transfer at the initial state". Newcastle Working Papers in Linguistics 17: 220-236 .

Sanchez, 1., and jaRvis, s. 2008 . "The use of picture stories in the investigation of crosslinguistic influence". TESOL Quarterly 42: 329-333 .

Sayehli, s. 2001 . Transfer and syntax: a study on the acquisition of German word order by Swedish native speakers. Ms ., Lund University .

SchönpFlug, u. 2000 . "Word-fragment completion in the second (German) and third (English) language . A contribution to the organisation of the trilingual speaker's lexicon". The Acquisition of a Third Language . Eds . j. cenoz, and u. jessneR . Clevedon: Multilingual Matters . 121-142.

. 2003 . "The transfer-appropriate processing approach and the trilingual's organisation of the lexicon" . The Multilingual Lexicon . Eds . j. cenoz, b. huFeisen and u. jessneR Clevedon: Multilingual Matters . 27-44

SikogukiRa, M. 1993. "Influence of languages other than the L1 on a foreign language: A case of transfer from L2 to L3" . Edinburgh Working Papers in Applied Linguistics 4: 110-132 .

StRatilaki, s. 2006 . "Representations of plurilingual competence and language use in dynamic trilingual education" . Zeitschrift für Interkulturellen Fremdsprachenunterricht 11 . Online article .

taube-SchiFF, M., and SegaloWitz, n. 2005 . "Within-language attention control in second language processing". Bilingualism: Language and Cognition 8: 195-206 .

tayloR, b. 1975 . "The use of overgeneralization and transfer learning strategies by elementary and intermediate students of ESL" . Language Learning 25: 73-107 .

toRRas, M.R., navés, t., celaya, M.l., and péRez-Vidal, c. 2006 . "Age and interlanguage development in writing". Age and the Rate of Foreign Language Learning. Ed . c. Muñoz. Clevedon: Multilingual Matters . 156-182 . 
tRévisiol, p. 2006. "Influence translinguistique et alternance codique en français L3: Role des L1 et L2 dans la production orale d'apprenants japonais" . Acquisition et Interaction en Langue Etrangère, 13-43 .

vogel, t. 1992 . "Englisch und Deutsch gibt es immer Krieg . Sprachverarbeitungsprozesse beim Erwerb des Deutschen als Drittsprache" . Zielsprache Deutsch 23: 95-99 .

WilliaMs, s., and haMMaRbeRg, b. 1998 . "Language switches in L3 production: implications for a polyglot speaking model". Applied Linguistics 19: 259-333 . 